\title{
The future of supply chain planning: Closing the gaps between practice and promise
}

\author{
Patrik Jonsson \\ Department of Technology Management and Economics \\ Chalmers University of Technology, Gothenburg \\ patrik.jonsson@chalmers.se \\ Jan Holmström \\ Department of Industrial Engineering and Management \\ Aalto University, Helsinki \\ Jan.holmstrom@aalto.fi
}

\begin{abstract}
Purpose: The purpose is to develop a research agenda for supply chain planning (SCP) relevant to practice.

Design/methodology/approach: We critically evaluate academic literature on SCP in order to understand how problems are addressed in their particular context, what the outcomes are, and the mechanisms producing the observed outcomes. Four categories of SCP are studied: sales and operations planning (S\&OP), supply chain master planning, supply chain materials management, and collaborative materials management. We introduce the concept of enabling mechanisms to identify specific innovations in materials management and production management that can facilitate the future improvement of SCP.

Findings: The critical evaluation of current SCP theory presents very limited results that are of practical relevance. SCP is not presented as an intervention and the results are not in a form that is actionable for practitioners. The body of literature is almost absent in addressing problems according to context, it presents limited evidence of intended outcomes, and it fails to identify unintended outcomes. As a consequence, research is unable to bolster theoretical understandings of how outcomes - both intended and unintended - are achieved. In our forward-looking research agenda we leverage our understanding of the enabling mechanisms in order to propose research to make mature S\&OP and novel types of SCP implementable.
\end{abstract}

Research implications: The paper is an example of a structured approach to developing a research agenda that is relevant to practice and can be used more widely in logistics and supply chain management.

Practical implications: This paper presents a research agenda to close the gap between practice and promise in SCP.

Originality/value: We operationalize what constitutes practical relevance for an established field of research.

Keywords: Supply chain planning, sales and operations planning, supply chain master planning, supply chain materials management, collaborative materials management, design science

Paper type: Invited paper 
Full reference to article: Jonsson, P. and Holmström, J. (2016), "The future of supply chain planning: Closing the gaps between practice and promise", International Journal of Physical Distribution and Logistics Management, Vol. 46 No. 1 pp. 62-81, DOI: http://dx.doi.org/10.1108/IJPDLM-05-2015-0137

\section{Introduction}

Manufacturing companies, wholesalers, and retailers introduce supply chain planning (SCP) in an attempt to improve performance in operations and to better align operations and supply chain partners with business strategy (Stank et al., 2012; Tohamy et al., 2013). However, the outcomes of such efforts to integrate demand and supply through planning have fallen short of expectations, exposing a gap between practice and promise (see e.g., Alftan et al., 2015; Tate et al., 2015). For example, higher sales and operations planning (S\&OP) maturity levels are rarely implemented in practice (Viswanathan 2010) and we do not know what they require and what to expect from such implementations. Vendor managed inventories (VMIs) are used for a limited amount of items (Jonsson and Mattsson, 2015) and, despite lots of studies, it is not clear when and how to share planning information in supply chains (Sahin and Robinson, 2002; Jonsson and Mattsson, 2013). Moreover, numerous models and methods for optimizing supply chain master planning and multi-echelon stock decisions have been developed but several are not applicable in practice and the models are therefore only implemented to a limited extent in practice (Williams and Tokar, 2008).

The implementation of SCP addresses two of three key issues firms must resolve when managing their supply chains (Lambert and Cooper, 2000). The implementation of SCP determines the processes and level of integration a firm uses to manage its business and relationships. Supply chain design deals with the remaining issue of the relationship network structure. As a result, the potential benefits and competitive advantage (González-Loureiro et al., 2015) that can be gained from supply chain management (SCM) need to be achieved to a substantial degree through SCP. If the outcomes of SCP fall short of expectations, it is not just SCP that is not fulfilling its promise to the company but also SCM.

SCP is far from being a new concept and there is much research and practice development. Nevertheless, there still is a gap between practice and promise that research is not effectively addressing. Why is this? Is SCP too difficult a topic to tackle in practice? Mature SCP is challenging as it involves several functional areas and requires significant integration (both intra- and interorganizationally) - including processes, organization, information technology, people, performance measures, and so on. Or, is SCP too complex to research? We argue that SCP is neither too challenging to implement or to research. Both research on and practice of SCP could be improved through future research focusing on practice, with the ambition to close the gap between practice and promise.

The purpose of this article is to develop a research agenda in SCP relevant to current and future practice. We first demonstrate the weaknesses of the current literature on SCP in supporting companies in introducing planning appropriate to their needs. We identify how SCP theory falls short in setting expectations of outcomes from implementation, as well as in providing guidance on how to implement SCP. Furthermore, we investigate how the visibility of material flows and flexibility of production can be leveraged to improve SCP solutions in the future. To conclude, we present the research agenda.

\section{Current SCP theory does not support practice}

We define SCP as an implemented operations planning and control framework, system, process, or method with a supply chain scope. SCP has been characterized in the literature as a framework, process, system, or method for coordinating and synchronizing supply-facing and demand-facing activities in order to generate supply chain value through organizational collaboration (Oliva and Watson, 2011, p. 434) and/or optimization (Pibernick and Sucky, 2007). However, such a view of SCP is not sufficient to support practice. From a theoretical perspective, SCP needs to be evaluated as a 
Full reference to article: Jonsson, P. and Holmström, J. (2016), "The future of supply chain planning: Closing the gaps between practice and promise", International Journal of Physical Distribution and Logistics Management, Vol. 46 No. 1 pp. 62-81, DOI: http://dx.doi.org/10.1108/IJPDLM-05-2015-0137

specific management intervention that is implemented, managed, and actively developed. Practically relevant SCP theory supports managers and other actors in achieving desired and intended outcomes by taking into account the particular setting or context wherein the process or system is used and by understanding how particular mechanisms produce outcomes. It also supports them by revealing unintended outcomes. Developing theory that is actionable in practice accords to calls of, for example, Christensen and Raynor (2003) and Halldórsson et al. (2015). Figure 1 presents the four general components (context, intervention, mechanism, and outcome [CIMO]) of practically relevant SCP theory, based on a framework much used in solution design and intervention oriented research (Pawson and Tilley, 1997; Denyer et al., 2008). This framework used is known as the CIMO framework.

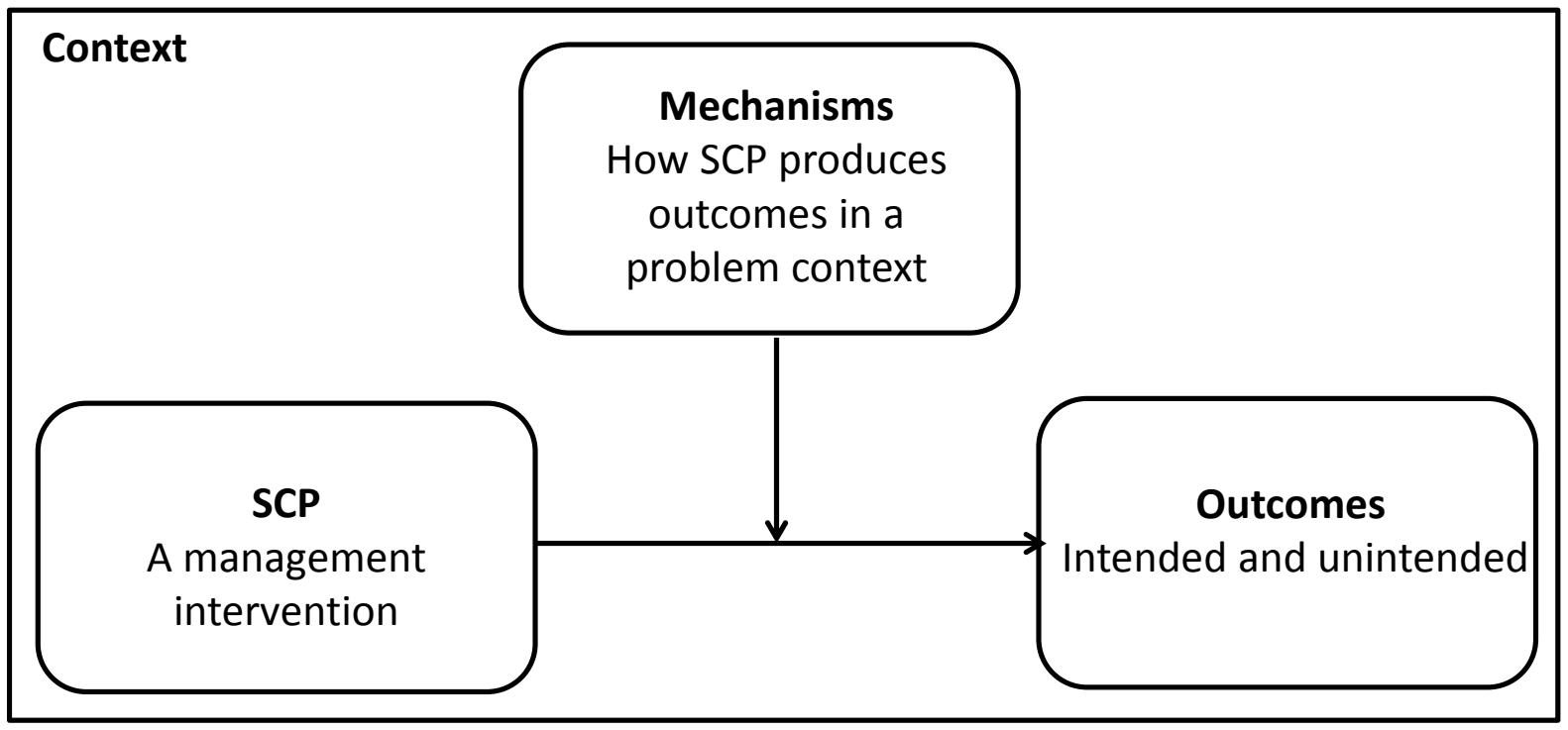

Figure 1. The components of practically relevant SCP theory

In the evaluation of SCP theory we set out by identifying the following four broad categories of SCP practice: sales and operations planning (S\&OP), supply chain master planning (SCMP), supply chain materials management (SCMM), and collaborative materials management (CMM). The first two chiefly concern tactical planning, while the two last concern operational planning and control. We identify S\&OP as a medium- to long-term cross-functional process aimed at coordinating demand and supply planning. SCMP is medium-term production planning in multisite production, distribution warehouse, and transportation networks (Pibernik and Sucky, 2007), where the focus is largely on using analytical models and optimization. SCMM is the operational planning and control of inventory replenishment in supply chains, where the focus is largely on using analytical models and optimization. CMM is the operational planning and control of inventory replenishment in supply chains, where the focus is largely on information sharing and collaboration between supply chain actors.

For each of these SCP types we evaluate if current SCP literature addresses their problems in specific contexts and how outcomes are achieved (through interventions that trigger mechanisms) in those contexts. The evaluation follows the structure presented in Figure 1. By focusing on problems in specific contexts we try to identify why the SCP types were originally developed and define the situations in which a framework, process, system, or method is intended to be implemented. Furthermore, articulating problems according to context is the basis for evaluating the success or failure of SCP interventions. The evidence of outcomes, in turn, supports the analysis of how mechanisms generate outcomes in the context and the development of theoretical understanding. 
Full reference to article: Jonsson, P. and Holmström, J. (2016), "The future of supply chain planning: Closing the gaps between practice and promise", International Journal of Physical Distribution and Logistics Management, Vol. 46 No. 1 pp. 62-81, DOI: http://dx.doi.org/10.1108/IJPDLM-05-2015-0137

The outcomes in need of theoretical explanation are the intended outcomes (when the intervention works as designed) and the unintended outcomes (when it does not).

Figure 2 summarizes the overall evaluation of practical relevance. The general finding is that the literature presents very limited results that are of interest for developing practically relevant SCP theory. SCP is not presented as an intervention and results are not in a form that is actionable for practitioners. The body of literature on SCP is almost absent in addressing problems according to context, it presents limited evidence of intended outcomes, and it fails to identify unintended outcomes. We identify conflicts between analytical and empirical research concerning SCP interventions that limit the theoretical understandings of mechanisms generating SCP outcomes and developments. While analytical models based on SCP interventions fail to address problems in the context of prospective adopting companies, empirical studies show little understanding of how much maturity should be sought and what outcomes should be expected in given contexts. In general, research that describes SCP as a practice tends to assume that desirable outcomes simply follow from the introduction of SCP in any supply chain, while research investigating the conditions and antecedents of achieving desirable outcomes do not investigate SCP as a practice but as part of some more abstract concept, such as integration or coordination. As a consequence, the literature is not able to bolster theoretical understandings of how SCP outcomes - both intended and unintended are achieved. Next we present some more details of the literature evaluation related to each SCP type.

\footnotetext{
Context

- The purpose of specific SCP interventions not related to context.

- The sought maturity level not related to context.

- The expected outcomes not related to context.

- Limited insight into the problems and challenges of implementation.
}

Mechanisms and theoretical understanding

- A limited understanding of how intended and unintended outcomes are generated in SCP interventions.

- Theoretical understanding is lacking because SCP interventions are not studied in context, and evidence of outcomes is lacking.

SCP

- SCP is not studied as an intervention.

- The content and purpose of SCP is not clearly articulated.

- SCP is not 'actionable' in practice.

\section{Outcomes}

- Limited evidence of intended outcomes.

- An optimized outcome in models, but a lack of empirical evidence. Unintended outcomes are not recognized.

Figure 2. Practical relevance gaps in current SCP theory

\section{SCP types}

The first step of the evaluation is to identify the categories of SCP practices to be evaluated. Without defining what is implemented, it is impossible to evaluate outcomes, or determine the problems addressed and how outcomes are achieved in particular settings. Using our SCP definition, we identified and defined S\&OP, SCMP, SCMM, and CMM as four broad categories. 
Full reference to article: Jonsson, P. and Holmström, J. (2016), "The future of supply chain planning: Closing the gaps between practice and promise", International Journal of Physical Distribution and Logistics Management, Vol. 46 No. 1 pp. 62-81, DOI: http://dx.doi.org/10.1108/IJPDLM-05-2015-0137

Academic literature on S\&OP is limited, as shown in reviews by Tavares Thomé et al. (2012) and Tuomikangas and Kaipia (2014). If collaborative forecasting is included as part of S\&OP, then the body of literature is somewhat extended (Eksoz et al., 2014). The literature describes S\&OP according to the management dimensions of vision, strategy, governance, organization, process, technology, and performance. Implementing S\&OP rapidly becomes complex as it involves many organizations and organizational levels. The literature outlines implementation at different S\&OP maturity levels by using maturity frameworks (Lapide, 2005; Grimson and Pyke, 2007; Tohamy et al., 2013). Lower S\&OP maturity levels focus on the problem of forecasting collaboration between demand-and supply-facing functions, while more mature S\&OP maturity widens the problem scope to include both interorganizational planning and integrating S\&OP with financial, risk, and business planning. The literature emphasizes the role of mature S\&OP as a driver of business planning (Grimson and Pyke, 2007; Ivert and Jonsson, 2014) envisioning a coordinated enterprise and network decision-making to create value (Tohamy et al., 2013).

SCMP at its simplest introduces an analytical model using available information by a manufacturer or distributor, yet at its most complex can implement a new, integrated business process for collecting and analyzing supply chain data, requiring extensive changes in both organizational and IT systems. The extensive literature regarding SCMP is principally analytical, and most interventions proposed by the literature are based on network optimization - as reviews by Kouvelis et al. (2006) and Mula et al. (2006) show - and require advanced software applications (Jonsson et al., 2007). The literature elaborates upon centralized (Brown et al., 2001), decentralized (Poundarikapuram and Veeramani, 2004), and integrated SCMP-scheduling (Maravelias and Sung, 2009; Steinrucke and Jahr, 2012) decision-making models. Hybrid models (Pibernik and Sucky, 2007) and negotiation-based ones (Dudek and Stadtler, 2005) are other examples.

Literature on SCMM is abundant and primarily concerned with optimizing and analytically evaluating different types of inventory control models (that usually are not implemented) under particular conditions (which are often not field conditions). In their review of inventory management literature, Williams and Tokar (2008) identify a focus on the traditional reorder point model, extended to incorporate transportation and warehousing factors, buyer-supplier relationships, and reverse flows, including portfolio effects on supply chain performance. An exemplary SCMM intervention introduces the joint optimization of transportation, warehousing, and inventory decisions for reducing aggregate safety stocks via centralized stocking, transshipment, and cross-docking (e.g., Waller et al., 2006).

Research on CMM is recent but evolving, as the literature reviews of Williams and Tokar (2008) and Tavares Thomé et al. (2014a) illustrate. CMM introduces processes or systems for information sharing and visibility between supply chain actors. Many times CMM changes decision-making rights and the responsibilities of materials management are transferred in the supply chain, normally upstream. Academic literature is a mix of analytically, simulation, and empirically based research that describes demand-related information sharing and specific collaborative programs, including quick response, efficient consumer response, continuous replenishment, VMI, distributor integration, and collaborative forecasting and replenishment (CPFR). Most descriptions take multifocal or dyadic perspectives involving wholesaler-retailer or producer-producer relations. Analytical literature focuses on the value of collaboration and optimal ordering decisions (Xu et al., 2015). Typical topics of conceptual, empirical, case, and survey literature are maturity and descriptive frameworks (SkjoettLarsen et al., 2002; Ståhl-Elvander et al., 2007) and the antecedents and enablers of implementation (Danese, 2006a; Danese, 2006b; Claassen et al., 2007). 
Full reference to article: Jonsson, P. and Holmström, J. (2016), "The future of supply chain planning: Closing the gaps between practice and promise", International Journal of Physical Distribution and Logistics Management, Vol. 46 No. 1 pp. 62-81, DOI: http://dx.doi.org/10.1108/IJPDLM-05-2015-0137

\section{Problems, outcomes, and theoretical understanding}

The literature clarifies the general problem that different types of SCP are designed to solve but does not specify how to configure a solution or what to expect from implementation in a specific context. The study of Goh and Eldridge (2015) is one of few studies explaining how S\&OP configuration and outcomes relate to context. So still, little is known about how supply chain complexity, culture, and business models impact appropriate S\&OP maturity levels (Ivert and Jonsson, 2014; Tavares Thomé et al., 2012; Tavares Thomé et al., 2014b). For SCMP and SCMM, literature recognizes that vertical integration across several supply chain tiers or wide production networks enable implementation (Kouvelis et al., 2006; Pibernik and Sucky, 2007; Rudberg and Thulin, 2008; Jonsson et al., 2013), yet literature does not question whether or how these intervention types are practical at lower levels of vertical integration. $\mathrm{CMM}$ research has yet to provide a clear, full understanding of how to configure $\mathrm{CMM}$ and what to expect from CMM in different contexts, despite recognizing the problem (e.g., Holweg et al., 2005; Dong et al., 2007; Danese, 2011; Jonsson and Mattsson, 2013; Xu et al., 2015).

Evidence of outcomes from introducing different types of SCP is limited, even though the intended outcomes of the respective SCP type are discussed in the literature. When outcomes are reported it is often from the limited perspective of a single firm or, at best, for a single planning task in a dyad. Evidence of outcomes is very limited for SCP with a clear supply chain or network scope and involving multiple organizations, for example coordinating transport and production planning, as shown by Kouvelis et al. (2006), Gumus and Guneri (2007), Williams and Tokar (2008), and Tavares Thomé et al. (2012). For CMM, Kauremaa et al. (2009) and Tanskanen et al. (2015) provide rare examples of presenting outcomes of an SCP intervention from multiple supply chain actor perspectives.

However, the outcomes of many SCP types are not always as intended, as seen in the low level of adoption in practice. We find that the recognition of unintended outcomes is particularly lacking for all SCP types, as seen in the lack of research on adoption. The reviewed types of SCP are far from new; most concepts and models have been available in textbooks and known among consultants for several decades. The literature, however, reveals few studies of SCP adoption in practice, signifying a lack of understanding of how SCP is implemented and used. Experience and research (e.g., Tate et al., 2015; Viswanathan, 2010) suggest that simple, lower maturity levels of S\&OP are adopted to a large extent, while advanced and mature S\&OP levels remain uncommon. For CMM, especially VMIs, there are indications of widespread adoption in practice, though only on a small scale in their supply chains (e.g., Jonsson and Mattsson, 2015). The adoption of SCMP is very much driven by the implementation of advanced software in vertically integrated production and distribution networks. The same goes for SCMM, and we expect the adoption levels of SCMP and SCMM to be significantly lower than those of S\&OP and CMM. Case-based studies (e.g., Oliva and Watson, 2011; Ivert and Jonsson, 2014) contribute with sporadic insights into unintended SCP outcomes, though all SCP types lack a clear, full understanding of what unintended outcomes occur and how they occur.

The present literature cannot help practitioners by explaining how intended and unintended outcomes are produced by SCP in specific contexts. Theoretical understanding of SCP is lacking because SCP is seldom studied in context and evidence of outcomes is not often reported. To effectively support practice, research should be able to propose and identify the mechanisms through which SCP results in outcomes in specific contexts. This is what Merton (1957) calls mid-range theory development, and it is almost entirely lacking for the studied SCP types.

Mechanisms are processes, behaviors, and responses that are triggered by interventions. For example, $\mathrm{CMM}$ implementation is an intervention that is supposed to trigger collaboration, and collaboration is how CMM produces intended outcomes in terms of the better allocation of inventories. CMM may 
Full reference to article: Jonsson, P. and Holmström, J. (2016), "The future of supply chain planning: Closing the gaps between practice and promise", International Journal of Physical Distribution and Logistics Management, Vol. 46 No. 1 pp. 62-81, DOI: http://dx.doi.org/10.1108/IJPDLM-05-2015-0137

also trigger other behaviors than collaboration that lead to unintended outcomes (e.g. customers hoard products that are in short supply). SCP outcomes are often presented and studied in the abstract - without a focus on a specific SCP intervention. For example, supply chain integration (e.g., Flynn et al., 2010) is explained using constructs (such as organizational structure, internal relational behavior, customer relational behavior, top management support, information sharing) and performance management alignment and coordination is indicated without specifying and focusing on either the SCP type or the context of implementation (e.g., Wong et al., 2012). The types and roles of intra- and inter-organizational integration for generating outcomes and the relationships between them are topics that have been emphasized and studied extensively but with quite varying results because of the lack of focus on the SCP type and context specification (see e.g., Flynn et al., 2010; Zhao et al., 2011; Leuschner et al., 2013: Williams et al., 2013). For S\&OP, some case studies can be found suggesting explanations for observed outcomes, such as internal relational behavior, top management support, and performance management (Oliva and Watson, 2011; Ivert and Jonsson, 2014; Goh and Eldridge, 2015). For CMM, there are studies suggesting explanations, such as supplier and customer relational behavior and information sharing (Claassen et al., 2007; Danese, 2006b).

We conclude that although the literature suggests the type of mechanisms that contribute to SCP outcomes (Wong et al., 2012), how these outcomes are generated in specific contexts is not well understood. A particular weakness of analytical and simulation-based literature, which is a substantial part of SCMP and SCMM literature, is its general failure to consider behavioral issues and managerial decision making in SCP intervention design and the analysis of outcomes (Williams and Tokar, 2008).

\section{Closing the gap through innovation and simplification}

A key finding of the SCP literature evaluation is the lack of understanding of how implementation produces outcomes in specific contexts. We propose approaching the implementation of SCP in a firm as a combinatorial intervention (Arthur, 2009), in other words, an intervention that relies on processes and systems that are already implemented (Lambert and Cooper, 2000). For example, introducing SCMP relies on a common classification of stock keeping units (SKUs) across inventory locations and a common planning calendar for production sites. Multinationals introducing SCMP for the first time spend a significant effort in first implementing the prerequisite solutions. Changes in such enabling processes and systems have shaped SCP and will continue to shape SCP in the future. In the following we investigate how changes in two particular processes - materials management (MM) and production management (PM) - present opportunities to innovate in SCP and, in particular contexts, simplify and even reduce the need for SCP. Consequently, to close the gap between practice and promise there is a need for understanding how the scope of SCP can be extended through innovations and through simplifying implementation. Such an approach and understanding could move the research focus from understanding the present to driving the future practice of SCP.

\section{How change in MM enables innovation in SCP}

Practice in many industries has for some time moved in a direction where the scope of current SCP is insufficient (Hayes et al., 2004). The scope of current SCP is insufficient in contexts where delivery includes service elements, such as installation, systems integration, project management, and aftersales. For example, in commercial vehicle manufacturing, after-sales and refurbishments are today a very significant and growing parts of the business (e.g., Book et al., 2012). In such environments, current SCP struggles to effectively deal with the demand generated by individual customers and individual products. In this subsection we will focus on the opportunity for innovation enabled by a shift from anonymous to individualized products in MM. 
Full reference to article: Jonsson, P. and Holmström, J. (2016), "The future of supply chain planning: Closing the gaps between practice and promise", International Journal of Physical Distribution and Logistics Management, Vol. 46 No. 1 pp. 62-81, DOI: http://dx.doi.org/10.1108/IJPDLM-05-2015-0137

Innovation in SCP is enabled when products are individualized and tracked, and by the design of intelligent products including information processing and connectivity (Meyer et al., 2009). Conventional MM identifies material items as SKUs in inventory locations (Silver et al., 1997; Rönkkö et al., 2007) where material accounts are used to register movements of SKUs. In the material flow, individual items are anonymous and only classified, not identified (Parsons and Wand, 2000). However, this visibility - enabled by the common classification of SKUs - only suffices when material flows are homogenous and replenishment mechanisms can be introduced to negotiate changes in demand, for example, for monitoring customer inventories to plan the use of limited capacities and buffer inventories (Småros et al., 2003).

Indicative examples of SCP innovations that increase the scope of planning based on item identification and product intelligence can be found in reverse supply chains and project delivery networks. Identifying individual parts in material flows (i.e., tracking) simplifies recall planning when products are defective, as well as facilitates the reuse and remanufacture of parts (Meyer et al., 2009). SCP for product recalls is an example of a planning task with potentially profound impacts but limited research has been done on it and there is fragmented understanding of it (Wowak and Boone, 2015). Item identification and tracking also enable identifying emerging problem situations in project deliveries and planning appropriate responses (Holmström et al., 2011). In project deliveries, item identification enables responding to design changes with recalls and reallocations so that project schedules can be fulfilled on time with less material loss and obsolescence (Ala-Risku et al., 2010).

When material flows begin to contain items that can process information and communicate - that is, are intelligent and connected to the Internet of Things (Meyer et al., 2009) - it becomes incrementally possible to communicate installation status and chart a project's progress in real time. The opportunity for SCP innovation is using that information for coordinating engineering changes, materials flows, and project delivery planning (Ala-Risku et al., 2010). Intelligent items also allow the incorporation of transportation networks and in-transit material flows in the scope of SCP (Kärkkäinen et al., 2004; Arnäs et al., 2013). In planning maintenance and service operations, intelligent items offer a new source of demand information that can be used for performance-based service delivery and targeted upgrades (Holmström et al., 2010a).

How change in PM enables the simplification of SCP

The simplification of SCP is a second mechanism that can be invoked to extend the scope of SCP and close the gap between practice and promise. Our evaluation of SCP literature indicated that a low level of adoption is an unintended outcome, for example, of more mature S\&OP (Viswanathan, 2010). Here we posit that difficulty in implementing SCP in supply chains that have complex structures and multiple levels is a possible reason for low levels of adoption. As a mechanism to facilitate adoption of more mature and wider-scope SCP interventions, we propose simplification of SCP based on change in PM.

The proposition is based on the notion that the type of SCP intervention that is needed and how much effort it requires to implement depends on the flexibility of production. Simplification of SCP enabled by change in PM is based on the inventory and dedicated tooling being replaced with more flexible practices, such as retooling practices of just-in-time (JIT) manufacturing and direct digital manufacturing (DDM).

In conventional manufacturing, tools and processes are inflexible, which poses the need for CMM and SCMM interventions to ensure that products are produced in time and in sufficient lot sizes to designated locations in order to fulfill forecasted demand. This is particularly challenging in product introductions where supply chain structures are deep and wide (Holmström et al., 2006). Each facility 
Full reference to article: Jonsson, P. and Holmström, J. (2016), "The future of supply chain planning: Closing the gaps between practice and promise", International Journal of Physical Distribution and Logistics Management, Vol. 46 No. 1 pp. 62-81, DOI: http://dx.doi.org/10.1108/IJPDLM-05-2015-0137

can produce only a limited range of products for which it has been established and/or equipped. From a planning perspective, this circumstance means that products cannot be shifted among locations unless product-specific assets are moved or investments made. The setup also affects costs and creates the need for production in batches and keeping an inventory. Such inflexibility in shifting production increases the importance of SCP focused on coordinating speculative production planning and building up inventories across supply chains in anticipation of demand (e.g., Christopher and Holweg, 2011).

Yet, via innovations in PM, it becomes possible to increase the flexibility of production facilities. Already established knowledge and practice of JIT manufacturing, for example, is an important enabler for expanding the scope of SCP to include production decisions and responsive planning. A key practice in JIT manufacturing is increasing flexibility by reducing set-up times and expediting retooling, which is a means of increasing the flexibility of production by focusing on quicker set-up and retooling to allow more locations to produce products. This facilitates shifting production among locations in response to demand, and improves negotiating uncertainties in demand (Christopher and Holweg, 2011). Enabling such allocation decisions in turn enhances the potential of SCMP and more mature S\&OP interventions.

We expect production flexibility as a driver of simplified SCP to be far more common in the future. DDM technologies such as additive manufacturing are already used to facilitate faster, more costeffective tool making. Production tools - for example, injection molds - can be produced using additive manufacturing (i.e., 3-D printing) directly from digital product models (Wohlers, 2009). As in JIT manufacturing, rapid tooling improves production flexibility and simplifies SCP. More flexible tooling in turn allows new products to be produced in many different locations, possibly closer to customers, simplifying planning through postponement and simultaneous ramping up and down of products in facilities nearer to customers.

Early examples of the impact of DDM indicate a shift of planning efforts toward production and away from inventories and material flows. Put differently, flexible production allows substituting speculative production and inventory planning with responsive, possibly postponed production (Holmström et al., 2010b). DDM's ability to produce parts without batch constraints could significantly reduce the need for inventories and other conventional logistics activities. For complex products such as machinery, DDM technology allows the production of assembly-ready kits of parts close to assembly lines and with far simpler material requirements planning (e.g., planning raw materials instead of components) and production planning (e.g., planning to directly produce kits to order instead of components to stock and kit to order) (Holmström et al., 2015).

\section{Extending the scope of SCP through innovation and simplification}

Change in $\mathrm{MM}$ and $\mathrm{PM}$ can thus be seen as driving a greater planning scope through innovation and simplification, as outlined in Figure 3. Here, the dotted triangle indicates the area of current scope of SCP as enabled by common PM and MM practice. In terms of the visibility of flows and flexibility of production, current practice hinders reaching higher-maturity S\&OP and realizing new, innovative SCP interventions. It is difficult to implement higher-maturity S\&OP when production facilities are not responsive to changes in demand and strategy, and innovation in SCP is inhibited by a lack of innovation in MM and PM. SCMP operates at the greatest limit of what is possible, given common MM and PM practice - its applicability and effects can be improved by changes in MM and PM. Points within the triangle depict past enabling changes in MM and PM for SCP interventions of increased scope. Points outside the triangle indicate still-emerging MM and PM practices, which are future opportunities for enabling change in the scope of planning. 
We propose that innovations for overcoming the current limitations in visibility and flexibility promise to de-emphasize problems currently addressed by SCP and, at the same time, enable innovation and simplify implementation of SCP. An example of an SCP innovation is leveraging item tracking and intelligent products for the planning of reallocation and reuse of materials in project delivery (AlaRisku et al., 2010). In contrast, an example of SCP simplification is leveraging DDM to simplify the structure of spare parts supply chains and the planning of after-sales (Holmström et al., 2010).

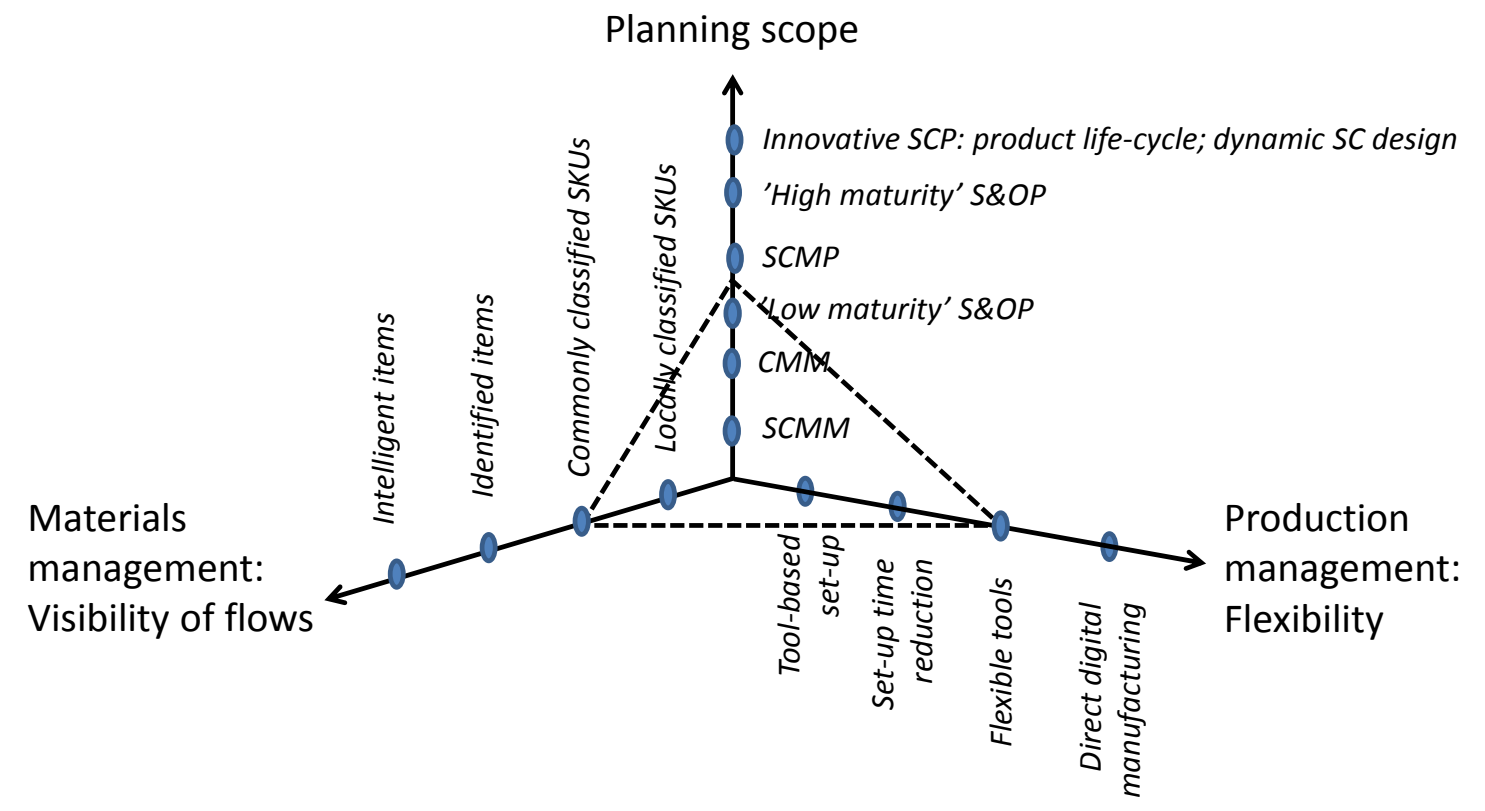

Figure 3. The visibility of material flows and the flexibility of production expand the scope of SCP; the current scope of SCP practice appears within the dotted triangle.

Many tasks related to SCP can be simplified and automated as material flow visibility and production flexibility increase. When flexible production responds to demand triggered by the visibility of inventories or intelligent products, there is less need for detailed forecasting on long horizons. Concurrent improvement of flexibility and visibility also allow more frequent, optimized planning and rescheduling of supply resources. With more flexible production, closer to the point of demand, product ramp-ups and ramp-downs require less planning, if any at all. Suppliers who respond to demand closer to customers have less need for inventory management and multilevel inventory approaches. Local flexible production replaces SCP and inventory management with the direct response to demand, which even in special situations can occur via replenishment from production or made-to-order production.

More dynamic planning combined with improved flexibility in responding allows changing offerings to customers and furthers the need for innovation in SCP. An example of such positive feedback in extending SCP planning is the improved monitoring of performance (e.g., with intelligent products) combined with flexible production (e.g., DDM). This combination can be used in new types of planning tasks focused on planning product development according to the added value that product improvements provide to customers, that is to say, supporting demand-driven R\&D. With sufficient visibility and flexibility, product development and solution sales efforts can be postponed until demand emerges. Here, SCP becomes critical since postponement requires product development and solution sales that are co-planned, which represents a strategic use of SCP in driving change. 
Full reference to article: Jonsson, P. and Holmström, J. (2016), "The future of supply chain planning: Closing the gaps between practice and promise", International Journal of Physical Distribution and Logistics Management, Vol. 46 No. 1 pp. 62-81, DOI: http://dx.doi.org/10.1108/IJPDLM-05-2015-0137

SCP can be leveraged in sales and financial planning to systematically capture opportunities. The ultimate step for SCP involves integrating tactical and strategic decision making related to business planning, R\&D, and supply chain design. Driven by more dynamic and responsive planning, SCP can be refocused from fulfilling sales targets and customer orders to improving product life cycles and identifying how systems, as defined by supply networks and products in use, can be improved. Such SCP-driven planning intends to identify actions that can make the entire system more effective and/or sustainable over time. This purpose accords with the vision of the highest S\&OP maturity level at which SCP takes an outside-in perspective and is used for integrated and optimized financial, demand, and for supply planning to drive competitive advantage and business growth (Tohamy et al., 2013).

\section{The research agenda for practical relevance and cutting edge practice}

We now proceed to set a research agenda focusing on researchable topics in order to increase relevance and to contribute to cutting edge SCP practice. The proposed research agenda is designed to help the academic research community to address the gap between SCP practice and its promise by highlighting the need for research focusing on how and when desired outcomes can be achieved. This, in turn, will enable academic research to begin contributing to the development of cutting edge practices. Figure 4 illustrates the goals for our proposed research agenda: (1) theorizing and understanding of how present SCP generates outcomes, (2) SCP innovations and simplifications leveraging the changes of enabling mechanisms (e.g., in MM [visibility] and PM [flexibility]), (3) implementing innovative and/or simplified SCP as a driver of competitive advantage.

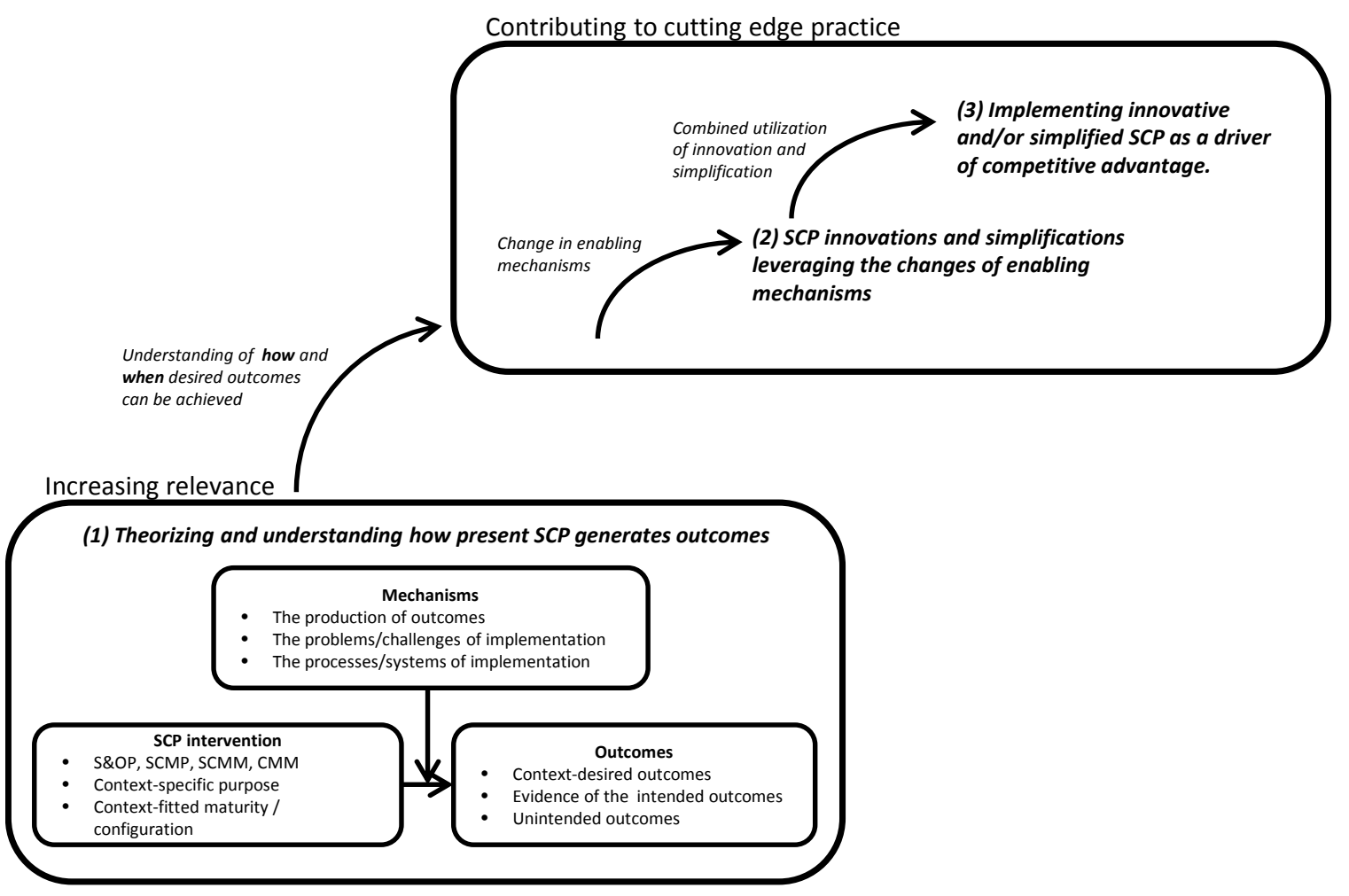

Figure 4. Increasing the relevance of present SCP research will enable academic research to begin contributing to cutting edge practices 
Full reference to article: Jonsson, P. and Holmström, J. (2016), "The future of supply chain planning: Closing the gaps between practice and promise", International Journal of Physical Distribution and Logistics Management, Vol. 46 No. 1 pp. 62-81, DOI: http://dx.doi.org/10.1108/IJPDLM-05-2015-0137

First step: The agenda for increasing practical relevance

Based on the evaluation of current SCP theory (summarized in Figure 2), we identified significant knowledge gaps that need to be addressed in order to increase the relevance of SCP research. The gaps in the present academic literature can largely be explained by the focus of the research community on individual studies and publishing papers. Much less effort has been expanded on assembling the big picture required for a rich theoretical understanding that covers the specific contexts, interventions, outcomes, and mechanisms producing outcomes. Questions that need to be addressed in SCP theory in order to support implementing firms with a practically relevant theoretical understanding of how present SCP generates outcome are:

- What is the purpose of specific SCP interventions in different contexts?

- What processes and systems do specific SCP interventions rely on for implementation in different contexts and for different purposes?

- What outcomes can be expected from SCP implementation, given a firm's specific context?

- What SCP maturity level should be sought, given a firm's context?

- What are the problems and challenges of SCP implementation and how can these be overcome?

- What evidence is there that SCP interventions produce the intended outcomes?

- What unintended outcomes of SCP interventions can be identified in different contexts?

When these questions supporting practice are effectively addressed it becomes possible to also begin to address the most challenging question for developing practically relevant theory:

- How do SCP interventions actually produce outcomes?

We propose that these questions are researchable by approaching SCP as a combinatorial intervention relying on the solution elements available to the firm (Teece, 2007). The objective should be to provide field-tested SCP theory (van Aken, 2004). Such SCP theory will ultimately be able to describe different types of SCP as combinatorial interventions (Arthur, 2009) that rely on processes and systems already implemented (Lambert and Cooper, 2000) to produce the intended outcomes in contexts that practitioners can recognize.

For developing field-tested theory, SCP interventions need to be identified, and case studies and case reviews conducted that focus on the outcomes of SCP interventions in different contexts and on how these outcomes are achieved. Case reviews, and also literature reviews, can be focused on identifying the CIMO framework of the case (Denyer et al., 2008; Pawson and Tilley, 1997). Henfridsson and Bygstad (2013) illustrate how to use such a framework to synthesize results from numerous case studies in order to explain how successful interventions produce outcomes in different contexts. A similar use of the CIMO framework would also be valuable for future SCP research in exploring, structuring, and conceptualizing how mechanisms generate outcomes in specific contexts (see, e.g., Ivert and Jonsson, 2014).

Closing the gap: The agenda for contributing to cutting edge practices

However, focusing on understanding current practice and collecting evidence will narrow, but not close, the gap between practice and promise. Research is also needed that leverages the understanding of how SCP produces outcomes in specific contexts in order to develop improved, cutting edge practices. 
Full reference to article: Jonsson, P. and Holmström, J. (2016), "The future of supply chain planning: Closing the gaps between practice and promise", International Journal of Physical Distribution and Logistics Management, Vol. 46 No. 1 pp. 62-81, DOI: http://dx.doi.org/10.1108/IJPDLM-05-2015-0137

To propose improvements in practice, an enabler such as visibility needs to be operationalized as something implemented in practice. For example, change in visibility can be operationalized in MM as the change from anonymous to individualized materials. In Figure 3 we made the attempt to operationalize how visibility and flexibility in terms of change in MM and PM practices enable innovation in SCP and the simplification of SCP. Through a combination of innovation and simplification in future SCP interventions and implementations, there will be a great opportunity for researchers to contribute to cutting edge solutions and to enable implementation of SCP as a driver of competitive advantage. We outline these research opportunities as two phases contributing to first and second order effects. The first order effect regards how enabling mechanisms (e.g., change in MM and PM practices) create opportunities for planning simplification and SCP innovations. The second order effect regards how such simplified and innovative SCP should be implemented for competitive advantage.

Expanding our view from change in $\mathrm{MM}$ and $\mathrm{PM}$, we recognize that there are many other ongoing and future societal, managerial, and technological changes (e.g., those related to computing platforms and customer relationship management [CRM]) that are potential enabling mechanisms for improved and innovative SCP. For example, change in the computing platform used by SCP is a likely further driver of change in SCP, with future use of in-memory computing expanding the scope of SCP. A potential mechanism for expanding the scope of SCP is the reduced processing times needed for optimization and what-if calculations, leading to the increased adoption of higher-maturity S\&OP among decision makers. However, standardized enterprise resource planning (ERP) platforms in production networks and dedicated planning software (with advanced planning and scheduling functionalities for optimization, what-if calculations, etc.) are basic computer applications still not widely implemented in practice and therefore constraining change towards the greater scope of SCP (see, e.g., Jonsson and Ivert, 2015).

Another process that SCP relies on, which we have not dwelled on but which is likely to be a significant driver of innovation, is CRM. The change from segmenting customers to individualizing them is similar to that of individualized products in MM and a potential input process for demand-driven R\&D. Consequently, changes in CRM and computing platforms are additional dimensions that could enable the simplification and innovation of SCP, and thus be added to Figure 3 as mechanisms enabling the widening scope of SCP. Studying changes in enabling mechanisms and SCP improvements changes the focus from being on present SCP interventions and practices to being on the future of SCP improvement.

Examples of the research questions to be addressed in order to advance an improvement agenda for how changes in enabling mechanisms lead to innovations and simplifications, and how implementing innovative and/or simplified SCP drives competitive advantage are:

- How has change in enabling processes and systems shaped SCP in the past?

- What changes in enabling processes and systems have the potential to shape SCP currently and in the future?

- How can change in the enabling mechanisms (e.g., the increasingly detailed visibility of individual customers and individual products generated by improvements in CRM and MM) be used for innovative SCP?

- How can change in enabling mechanisms be leveraged to simplify SCP in different contexts? 
Full reference to article: Jonsson, P. and Holmström, J. (2016), "The future of supply chain planning: Closing the gaps between practice and promise", International Journal of Physical Distribution and Logistics Management, Vol. 46 No. 1 pp. 62-81, DOI: http://dx.doi.org/10.1108/IJPDLM-05-2015-0137

- How can a combination of innovation and simplification in SCP increase competitive advantage in different contexts?

The major methodological challenge for research with an improvement agenda is the nature of the phenomenon studied. To conduct research with the aim of improving practice the researcher needs access to current best practice, as well as to the cutting edge developments that enable what could be. Furthermore, opportunities for access increase with adoption. Only established interventions are easily studied in practice, while innovations and failed interventions are difficult to get access to and study. The study of what could be is, however, the most difficult. In response, research on SCP needs to include experiments and pilot studies of novel interventions and solution concepts not yet implemented in practice. Since SCP is a combinatorial intervention, research on the future of SCP cannot be restricted to current SCP practice but requires researchers to survey potentially related domains as enablers of innovation and simplification. Such research may be conducted as design science research (Holmström et al., 2009). This challenge of introducing a design science perspective is a difficult one, not least for empirical researchers trained to study what is out there at the expense of what could be.

The use of analytical and simulation-based approaches enables studying novel concepts not yet implemented in practice. Analytical studies focusing on non-traditional contexts and new types of models would be important for identifying the potential of new interventions and applications. We especially observe the potential for future studies to use methods of simulation that are suited for dealing with interventions in contexts difficult to model analytically, including the effects of partial visibility when only some customers collaborate or when only some parts can be produced using more flexible production methods. The logical analysis of interventions and their mechanisms could, for example, be appropriate for exploring the potential effect of S\&OP in focusing sales and product development in more flexible supply chains or the effect of SCMM in redirecting material flows in more transparent supply chains. However, such approaches should be clearly related to follow-up studies more directly grounded in practice (e.g., pilot studies and conceptual system models).

\section{Conclusion}

In our critical review of SCP theory we conclude that research has in the main been satisfied with developing analytical models or empirically identifying enablers and antecedents (e.g., visibility of material flow and the flexibility of production) for outcomes (e.g., for supply chain integration, collaboration, or financial performance) without reference to implementable practices and practical contexts. This is not enough if the aim is to be relevant to practice. In addition to presenting models and identifying factors influencing outcomes, we also need to understand what was implemented and how and when an enabler of SCP, such as visibility, produces outcomes. This perspective operationalizes what constitutes practically relevant research and theory. For SCP it is field-tested theory (van Aken, 2004) that describes implementable types of SCP as combinatorial interventions relying on processes and systems that are already implemented to produce intended outcomes in contexts that practitioners can recognize. Our proposed research agenda for improving the practical relevance and contributing solutions to close the gap between the promise and practice of SCP, and for generating field-tested SCP theory, focuses on three related goals: (1) theorizing and understanding how present SCP generates outcomes, (2) SCP innovations and simplifications leveraging the changes of enabling mechanisms, (3) implementing innovative and/or simplified SCP as a driver of competitive advantage. 
Full reference to article: Jonsson, P. and Holmström, J. (2016), "The future of supply chain planning: Closing the gaps between practice and promise", International Journal of Physical Distribution and Logistics Management, Vol. 46 No. 1 pp. 62-81, DOI: http://dx.doi.org/10.1108/IJPDLM-05-2015-0137

We have presented an example of developing a research agenda that is relevant to practice. The theoretical perspective and the underlying CIMO framework was introduced in Figure 1 . The value for the wider field of logistics and supply chain management is showing how to operationalize practical relevance and use relevance to practice as the stepping stone for an improvement focused research agenda. The same theoretical perspective can more widely be used to guide the development of future research programs, detailed literature evaluations, and improvement agendas for intervention types and specific contexts. Using our SCP definition, the developed agenda concerns S\&OP, SCMP, SCMM and CMM. This perspective and framework is more widely relevant for the domains of logistics and supply chain research that can be clearly presented as management interventions - for example outsourcing, servitization, or supply chain design.

\section{References}

Ala-Risku, T., Collin, J., Holmström, J., and Vuorinen, J.P. (2010), "Site inventory tracking in the project supply chain: problem description and solution proposal in a very large telecom project," Supply Chain Management: An International Journal, Vol. 15 No. 3, pp. 252-260.

Alftan, A., Kaipia, R., Loikkanen, L., and Spens, K. (2015), "Centralised grocery supply chain planning: improved exception management," International Journal of Physical Distribution and Logistics Management, Vol. 45 No. 3, pp. 237-259.

Arnäs, P.O., Holmström, J., and Kalantari, J. (2013), "In-transit services and hybrid shipment control: the use of smart goods in transportation networks," Transportation Research Part C: Emerging Technologies, Vol. 36, pp. 231-244.

Arthur, W.B. (2009), The nature of technology: What it is and how it evolves, Simon \& Schuster, New York, NY.

Book, M., Ellul, E., Ernst, C., Frowein, B., Kreid, E., Rilo, R., Sticher, G., and Zablit, H. (2012), The European automotive aftermarket landscape: Customer perspective, market dynamics and the outlook to 2020, A report of the Boston Consulting Group, July 2012, The Boston Consulting Group.

Brown, G., Keegan, J., Vigus, B., and Wood, K. (2001), "The Kellogg company optimizes production, inventory and distribution," Interfaces, Vol. 31 No. 6, pp. 1-15.

Christensen, C.M. and Raynor, M.E. (2003), "Why hard-nosed executives should care about management theory", Harvard Business Review, Vol. 81 No. 9, pp. 1-10.

Christopher, M. and Holweg, M. (2011), "Supply chain 2.0: managing supply chains in the era of turbulence," International Journal of Physical Distribution and Logistics Management, Vol. 41 No. 1, pp. 63-82.

Claassen, M., van Weele, A.J., and van Raaij, E.M. (2007), "Performance outcomes and success factors of vendor managed inventories (VMI)," Supply Chain Management: An international journal, Vol. 13 No. 6, pp. 406-414.

Danese, P. (2006a), "Collaborative forms, information and communication technologies, and coordination mechanisms in CPFR," International Journal of Production Research, Vol. 44 No. 16, pp. 3207-3226.

Danese, P. (2006b), "The extended VMI for coordinating the whole supply network," Journal of Manufacturing Technology Management, Vol. 17 No. 7, pp. 888-907.

Danese, P. (2011), "Towards a contingency theory of collaborative planning initiatives in supply networks," International Journal of Production Research, Vol. 49 No. 4, pp. 1081-1103.

Denyer, D., Tranfield, D., and van Aken, J.E. (2008), "Developing design propositions through research synthesis," Organization Studies, Vol. 29 No. 3, pp. 393-413. 
Full reference to article: Jonsson, P. and Holmström, J. (2016), "The future of supply chain planning: Closing the gaps between practice and promise", International Journal of Physical Distribution and Logistics Management, Vol. 46 No. 1 pp. 62-81, DOI: http://dx.doi.org/10.1108/IJPDLM-05-2015-0137

Dong, Y., Xu, K., and Dresner, M. (2007), "Environmental determinants of VMI adoption: an exploratory analysis," Transportation Research Part E, Vol. 43, pp. 355-369.

Dudek, G. and Stadtler, H. (2005), "Negotiation-based collaborative planning between supply chain partners," European Journal of Operational Research, Vol. 163 No. 3, pp. 668-87.

Eksoz, C., Mansouri, A., and Bourlakis, M. (2014), "Collaborative forecasting in the food supply chain: a conceptual framework," International Journal of Production Economics, Vol. 158, pp. 120135.

Flynn, B., Huo, B., and Zhao, X. (2010), "The impact of supply chain integration on performance: A contingency and configuration approach," Journal of Operations Management, Vol. 28, pp. $58-71$.

Goh, S.H. and Eldridge, S. (2015), "Supplier integration in sales and operations planning: Evidence from the Asia Pacific region," International Journal of Physical Distribution and Logistics Management, Vol. 45 No. 9/10, pp. 861-886.

González-Loureiro, M., Dabi, M., and Kiessling, T. (2015), "Supply chain management as the key to a firm's strategy in the global marketplace: trends and research agenda," International Journal of Physical Distribution and Logistics Management, Vol. 45 No. 1/2, pp. 159-181.

Grimson, A. and Pyke, D. (2007), "Sales and operations planning: an exploratory study and framework," International Journal of Logistics Management, Vol. 18 No. 3, pp. 322-346.

Gumus, T. and Guneri, F. (2007), "Multi-echelon inventory management in supply chains with uncertain demand and lead times: literature review from an operational research perspective," Journal of Engineering Manufacture, Vol. 221, pp. 1553-1570.

Halldórsson, A., Hsuan, J., Kotzab, H. (2015), "Complementary theories to supply chain management revisited - from borrowing theories to theorizing", Supply Chain Management: An International Journal, Vol. 20 No. 6.

Henfridsson, O. and Bygstad, B. (2013), "The generative mechanisms of digital infrastructure evolution," MIS Quarterly, Vol. 37 No. 3, pp. 907-931.

Holmström, J., Brax, S., and Ala-Risku, T. (2010a), "Comparing provider-customer constellations of visibility-based service," Journal of Service Management, Vol. 21 No. 5, pp. 675-692.

Holmström, J., Holweg, M., Khajavi, S., and Partanen, J. (2015), "Printing the future: the implications of direct digital manufacturing for operations and supply chain management," Work in progress paper, Aalto University, Helsinki.

Holmström, J., Ketokivi, M., and Hameri, A.P. (2009), "Bridging practice and theory: a design science approach," Decision Sciences, Vol. 40 No. 1, pp. 65-87.

Holmström, J., Korhonen, H., Laiho, A., and Hartiala, H. (2006), "Managing product introductions across the supply chain: findings from a development project," Supply Chain Management: An international journal, Vol. 11 No. 2, pp. 121-130.

Holmström, J., Partanen, J., Tuomi, J., and Walter, M. (2010b), "Rapid manufacturing in the spare parts supply chain: alternative approaches to capacity deployment," Journal of Manufacturing Technology Management, Vol. 21 No. 6, pp. 687-697.

Holmström, J., Tenhiälä, A., and Kärkkäinen, M. (2011), "Item dwell time in project inventories: a field experiment," Computers in Industry, Vol. 62 No. 1, pp. 99-106.

Holweg, M., Disney, S., Holmström, J., and Småros, J. (2005), "Supply chain collaboration: making sense of the strategy continuum," European Management Journal, Vol. 23 No. 2, pp. 170181.

Ivert, K.L. and Jonsson P. (2014), "When should advanced planning and scheduling systems be used in sales and operations planning?" International Journal of Operations and Production Management, Vol. 34 No. 10, pp. 1338-1362. 
Full reference to article: Jonsson, P. and Holmström, J. (2016), "The future of supply chain planning: Closing the gaps between practice and promise", International Journal of Physical Distribution and Logistics Management, Vol. 46 No. 1 pp. 62-81, DOI: http://dx.doi.org/10.1108/IJPDLM-05-2015-0137

Jonsson, P. and Kjellsdotter Ivert, L. (2015), "Improving performance with sophisticated master production scheduling," International Journal of Production Economics, Vol. 168, pp. 118130.

Jonsson, P., Kjellsdotter, L., and Rudberg, M. (2007), "Applying advanced planning systems for supply chain planning: three case studies," International Journal of Physical Distribution and Logistics Management, Vol. 37 No. 10, pp. 816-834.

Jonsson, P. and Mattsson, S-A. (2013), "The value of sharing planning information in supply chains," International Journal of Physical Distribution and Logistics Management, Vol. 43 No. 4, pp. 282-299.

Jonsson, P. and Mattsson, S-A. (2015), "Inventory management: present practice and future research needs," Proceedings of the NOFOMA Conference 2015, Molde University College, Molde, Norway.

Jonsson, P., Rudberg, M., and Holmberg, S. (2013), "Centralised supply chain planning at IKEA," Supply Chain Management: An international Journal, Vol. 18 No. 3, pp. 337-350.

Kauremaa, J., Småros, J., and Holmström, J. (2009), "Patterns of vendor-managed inventory: findings from a multiple-case study," International Journal of Operations and Production Management, Vol. 29 No. 11, pp. 1109-1139.

Kouvelis, P., Chambers, C., and Wang, H. (2006), "Supply chain management research and production and operations management: review, trends and opportunities," Production and Operations Management, Vol. 15 No. 3, pp. 449-469.

Kärkkäinen, K., Ala-Risku, T., and Främling, K. (2004), "Efficient tracking for short-term multicompany networks," International Journal of Physical Distribution and Logistics Management, Vol. 34 No. 7, pp. 545-564.

Lambert, D.M. and Cooper, M.C. (2000), "Issues in Supply Chain Management," Industrial Marketing Management, Vol. 29, pp. 65-83.

Lapide, L. (2005), “An S\&OP maturity model," Journal of Business Forecasting, Vol. 24 No. 3, pp. 1528.

Leuschner, R., Rogers, D.S., and Charvet, F.F. (2013), "A meta-analysis of supply chain integration and firm performance," Journal of Supply Chain Management, Vol. 49 No. 2, pp. 34-57.

Maravelias, C.T. and Sung, C. (2009), "Integration of production planning and scheduling: overview, challenges and opportunities," Computers and Chemical Engineering, Vol. 72, pp. 52-67.

Merton, R. (1957), Social theory and social structure, Free Press, New York.

Meyer, G., Främling, K., and Holmström, J. (2009), "Intelligent products: a survey," Computers in Industry, Vol. 60 No. 3, pp. 137-148.

Mula, J., Poler, R., García-Sabater, J.P., and Lario, F.C. (2006), "Models for production planning under uncertainty: a review," International Journal of Production Economics, Vol. 103, pp. 271-285.

Oliva, R. and Watson, N. (2011), "Cross-functional alignment in supply chain planning: a case study of sales and operations planning," Journal of Operations Management, Vol. 29, pp. 434-448.

Parsons, J. and Wand, Y. (2000), "Emancipating instances from the tyranny of classes in information modeling", ACM Transactions on Database Systems, Vol. 25 No. 2, pp. 228-68.

Pawson, R. and Tilley, N. (1997), Realistic Evaluation, Sage, Thousand Oaks, CA.

Pibernik, R. and Sucky, E. (2007), "An approach to inter-domain master planning in supply chains," International Journal of Production Economics, Vol. 108, pp. 200-212.

Poundarikapuram, S. and Veeramani, D. (2004), "Distributed decision making in supply chains and emarketplaces," Production and Operations Management, Vol. 13 No. 1, pp. 77-92.

Rudberg, M. and Thulin, J. (2008), "Centralised supply chain master planning employing advanced planning systems," Production Planning and Control, Vol. 20 No. 2, pp. 158-167. 
Full reference to article: Jonsson, P. and Holmström, J. (2016), "The future of supply chain planning: Closing the gaps between practice and promise", International Journal of Physical Distribution and Logistics Management, Vol. 46 No. 1 pp. 62-81, DOI: http://dx.doi.org/10.1108/IJPDLM-05-2015-0137

Rönkkö, M., Kärkkäinen, M. and Holmström, J. (2007), "Benefits of an item-centric enterprise data model in logistics services: a case study," Computers in Industry, Vol. 58 No. 8, pp. 814-22.

Sahin, F. and Robinson, P. (2002), "Flow coordination and information sharing in supply chains: review, implications, and directions for future research," Decision Sciences, Vol. 33 No. 4, pp. 505-536.

Silver, E.A., Pyke, D.F., and Peterson, R. (1998), Inventory Management and Production Planning and Scheduling, Wiley, New York, NY.

Skjoett-Larsen, T., Thernoe, C., and Andresen, C. (2003), "Supply chain collaboration: theoretical perspectives and empirical evidence," International Journal of Physical Distribution and Logistics Management, Vol. 33 No. 6, pp. 531-549.

Småros, J., Lehtonen, J.M., Appelqvist, P., and Holmström, J. (2003), "The impact of increasing demand visibility on production and inventory control efficiency," International Journal of Physical Distribution and Logistics Management, Vol. 33 No. 4, pp. 336-354.

Stank, T.P., Esper, T.L., Crook, T.R., and Autry, C.W. (2012), "Creating relevant value through demand and supply integration," Journal of Business Logistics, Vol. 33 No. 2, pp. 167-172.

Steinrucke, M. and Jahr, M. (2012), "Tactical planning in supply chain networks with customer oriented single sourcing," International Journal of Logistics Management, Vol. 23 No. 2, pp. 259-279.

Ståhl-Elvander, M., Sarpola, S., and Mattsson, S-A. (2007), "Framework for characterizing the design of VMI systems," International Journal of Physical Distribution and Logistics Management, Vol. 37 No. 10, pp. 782-798.

Tanskanen, K., Holmström, J., and Öhman, M. (2015), "Generative Mechanisms of the Adoption of Logistics Innovation: The Case of On-site Shops in Construction Supply Chains," Journal of Business Logistics, Vol. 36 No. 2, pp. 139-159.

Tate, W., Mollenkopf, D., Stank, T., and Lago, A. (2015), "Demand and supply integration: bridging the great divide," Sloan Management Review, Vol. 56 No. 4, pp. 16-18.

Tavares Thomé, A.M., Hollmann, R.L., and do Carmo, L. (2014a), "Research synthesis in collaborative planning forecasting and replenishment," Industrial Management \& Data Systems, Vol. 114 No. 6, pp. 949-965.

Tavares Thomé, A.M., Scavarda, L.F., Fernandez, N.S. and Scavarda, A.J. (2012), "Sales and operations planning: a research synthesis," International Journal of Production Economics, Vol. 138, pp. 1-13.

Tavares Thomé, A.M., Sousa, R.S., and do Carmo, L. (2014b), "Complexity as contingency in sales and operations planning," Industrial Management and Data Systems, Vol. 114 No. 5, pp. 678695.

Teece, D.J. (2007), "Explicating dynamic capabilities: the nature and microfoundations of (sustainable) enterprise performance," Strategic Management Journal, Vol. 28 No. 13, pp. 1319-1350.

Tohamy, N., Tarafdar, D., Kohler, J., and Pukkila, M. (2013), Introducing the five-stage sales and operations planning maturity model for supply chain leaders, Gartner Group report, available at: https://www.gartner.com/doc/2587021/introducing-fivestage-sales-operations-planning (accessed 10 March 2015).

Tuomikangas, N. and Kaipia, R. (2014), "A coordination framework for sales and operations planning (S\&OP): synthesis from the literature," International Journal of Production Economics, Vol. 154, pp. 243-262.

Hayes, R., Pisano, G., Upton, D., and Wheelwright, S. (2004), Operations, Strategy and Technology: Pursuing the Competitive Edge, John Wiley and Sons, Hoboken, NJ. 
Full reference to article: Jonsson, P. and Holmström, J. (2016), "The future of supply chain planning: Closing the gaps between practice and promise", International Journal of Physical Distribution and Logistics Management, Vol. 46 No. 1 pp. 62-81, DOI: http://dx.doi.org/10.1108/IJPDLM-05-2015-0137

van Aken, J. (2004), "Management research based on the paradigm of the design sciences: the quest for field-tested and grounded technological rules," Journal of Management Studies, Vol. 41 No. 2, pp. 219-246.

Viswanathan, N. (2010), Sales and operations planning: Strategies for managing complexity with global supply chains, Aberdeen Group Report, available at: https://www.aberdeen.com (accessed 31 March 2011).

Waller, M., Cassady, C. and Ozment, J. (2006), "Impact of cross-docking on inventory in a decentralized retail supply chain," Transportation Research Part E, Vol. 42 No. 5, pp. 359-82.

Williams, B.D., Roh, J., Tokar, T. and Swink, M. (2013), "Leveraging supply chain visibility for responsiveness: The moderating role of integration," Journal of Operations Management, Vol. 31, pp. 543-54.

Williams, B.D. and Tokar, T. (2008), "A review of inventory management research in major logistics journals: themes and future directions," International Journal of Logistics Management, Vol. 19 No. 2, pp. 212-32.

Wohlers, T. (2009), Wohlers Report 2009: State of the Industry: Progress Report on Additive Manufacturing Technologies and Applications, Wohlers Associates, Fort Collins, CO.

Wowak, K.D. and Boone, C.A. (2015), "So many recalls, so little research: A review of the literature and road map for future research," Journal of Supply Chain Management, available at: DOI: $10.1111 / \mathrm{jscm} .12079$.

Wong, C., Skipworth, H., Godsell, J., and Achimugu, N. (2012), "Towards a theory of supply chain alignment enablers: a systematic literature review," Supply Chain Management: An international journal, Vol. 17 No. 4, pp. 419-37.

$\mathrm{Xu}, \mathrm{K}$. , Dong, Y., and Xia, Y. (2015), "'Too little' or 'too late': The timing of supply chain demand collaboration," European Journal of Operational Research, Vol. 241, pp. 370-80.

Zhao, X., Huo, B., Selen, W., and Yeung, J.H.Y. (2011), "The impact of internal integration and relationship commitment on external integration," Journal of Operations Management, Vol. 29, pp. 17-32. 